\title{
A Systematic Review of Physical Activity among People with Disabilities in Mainland China: From 1992 to 2013
}

\author{
Qi Si ${ }^{1}$, Linzhi Wang ${ }^{1}$, Haiqun Liu ${ }^{2}$, Paul D. Loprinzi ${ }^{3}$, Bradley J. Cardinal ${ }^{4}$ \\ ${ }^{I}$ Department of Sport and Exercise Science, College of Education, Zhejiang University, 148 Tianmushan Rd, \\ Hangzhou, CHINA. \\ ${ }^{2}$ Physical Education team, Zhejiang Special Education Vocational College, 527 Liuhu Rd, Hanghzou, CHINA. \\ ${ }^{3}$ Department of Health, Exercise Science and Recreation Management, The University of Mississippi, University, \\ MS 38677, USA. \\ ${ }^{4}$ Program in Kinesiology, School of Biological and Population Health Sciences, Oregon State University, 220 \\ Langton Hall, Corvallis, OR 97331-3302,USA.
}

*Corresponding Author: Qi Si, Department of Sport and Exercise Science, College of Education, Zhejiang University, 148 Tianmushan Rd, Hangzhou, CHINA.

\begin{abstract}
Context: Regular physical activity has increasingly been recommended to promote human health and wellbeing. However, information on participation in physical activities by people with disabilities is relatively scarce. The aim of this article is to conduct a systematically review of studies on physical activity among people with disabilities in mainland China from 1992 to 2013.
\end{abstract}

Evidence acquisition: In 2015, a search of three major Chinese electronic databases (CNKI, WANGFAN DATA, and VIP) was conducted for studies that examined physical activity among people with disabilities. The search included studies dating from January 1992 to December 2013. After applying inclusion criteria, 31 studies, all cross-sectional in design, were included in this review.

Evidence synthesis: The 31 studies included some self-reports of physical activity by people with disabilities $(N=5,982)$. The results from 9 of the 31 studies indicated that $12.7 \%$ of the participants in those studies $(N=760)$ had physical activity levels that met the standards recommended by national physical activity guidelines for China. Levels of physical activity among people with disabilities varied by gender, income, and education. Men and people with higher education and income levels were more physically active compared to women and those with lower education and income levels. In addition, people living in urban areas were more active than those living in rural areas.

Conclusions: Relatively low levels of physical activity were found among people with disabilities in mainland China. Further research on this special population is needed. Studies that employ rigorous standards for design and methodologies, including the use of objective physical activity measures, are recommended.

Keywords: Exercise, disabilities, cross-sectional design, physical activity recommendations, healthy lifestyles.

\section{INTRODUCTION}

The health benefits of participating in regular physical activity have been well documented. ${ }^{1}$ Current guidelines for adults call for physical activity of moderate intensity lasting at least 150 minutes per week or of vigorous intensity for at least 75 minutes per week. ${ }^{1}$ Despite strong and compelling evidence of health benefits associated with physical activity, globally only $31 \%$ of adults aged 15 and over (28\% of men and $34 \%$ of women) meet these physical activity guidelines ${ }^{2}$. This suggests that a significant proportion of people worldwide remain largely physically inactive. Not surprisingly, approximately 3.2 million deaths occur each year are attitributable to the negative health effects of insufficient physical activity. ${ }^{2}$

Evidence indicates that people with disabilities in particular are less likely than people without disabilities to be physically active. ${ }^{3}$ This further increases the risk of this special population 
developing functional limitations and secondary health conditions (e.g., obesity, depression, or social isolation). ${ }^{4}$ The low level of physical activity among people with disabilities raises serious concerns regarding their health and well-being. ${ }^{5}$ Understanding trends and physical activity in this population thus becomes important because such knowledge can help us development of better health promotion strategies for this population.

In 2006, approximately 83 million individuals in mainland China lived with different types of disabilities, accounting for $6.3 \%$ of the national population. ${ }^{6}$ Three decades of economic development, social progress, and improvement in health and medical services have contributed to some notable achievements in disability prevention and rehabilitation in China. However, physical activity studies targeting people with disabilities remain scarce. The first Chinese study that examined physical activity in people with disabilities was published in $1992,{ }^{7}$ but since then there has been no systematic review of studies reporting on physical activity in this population in China. To close this gap, this paper provides an overview of studies relevant to this topic that conducted between 1992 and 2013.

\section{EVIDENCE ACQUISITION}

\subsection{Selection and Identification of Studies}

A systematic search of the research on physical activity in people with disabilities in China was conducted in 2015. "A person with disabilities" was defined as someone with physical, cognitive, mental, sensory, emotional, or developmental impairment(s), or someone with some combination of these impairments. ${ }^{8}$ An adequate level of physical activity was defined using guidelines implemented in China, which call for at least 30 minutes of moderate-intensity physical activity at least 3 times a week. ${ }^{9}$

To identify relevant studies, the authors of the paper performed a systematic search using three major Chinese literature databases (CNKI, WANGFAN DATA, and VIP). Articles published between January 1992 and December 2013 were examined for reports on physical activity among people with disabilities. Primary search terms included "disabled person," "disabilities," "disability," and "underserved group" coupled with "physical activity" "exercise," "mass sports," and "leisure time physical activity." These terms were used to search text and subject headings wherever possible.

\subsection{Inclusion Criteria}

For this review, studies were considered to be eligible for inclusion if they:

1. Were written in the Chinese language

2. Were published in a peer-reviewed journal

3. Were published from 1992 to 2013

4. Clearly stated that the study of physical activity among people with disabilities was a research objective

Assessed physical activity using either self-reports or objective measures Studies were excluded if they were:

1. Theses; dissertations; conference abstracts, presentations, or proceedings; unpublished articles; or reports

2. Published in non-peer-reviewed publications

3. Rehabilitation studies, discussion articles, or program descriptions

4. Physical fitness assessments ${ }^{10}$

5. Studies were included or excluded after consensus was reached by two authors (qs and lzw).

\section{DATA EXTRACTION}

Data extraction was carried out via a standardized data extraction form completed by two independent reviewers. Information in the form included (a) article title and publication year, (b) study design, measures, and method of data analysis, (c) demographic characteristics of participants, and (d) data statistics on the prevalence of physical activity. When there was disagreement between the two reviewers, a consensus was reached after discussion with a third reviewer. 
Because study outcomes and types of analytic methods used varied by study, a meta-analysis was not performed.

\section{EVIDENCE SYNTHESIS}

Figure 1 provides an overall flow diagram for searching, screening, and identifying studies. The initial search of the databases yielded a total of 571 publications $(n=248$ from CNKI, $n=253$ from WANGFAN DATA, $n=70$ from VIP). After removing duplicates, ineligible studies, and unrelated studies, 29 studies met the criteria for this systematic review. Of these, 6 had research design, data analysis, or duplicate submission problems. After attempting to contact the authors of these studies, no reply was received; hence, these 6 studies were removed from this review. After screening relevant reference lists, a manual search for the full text of articles not identified in the original database search was conducted, and an 8 additional eligible articles were discovered. Thus, a total of 31 studies were eligible and included in the final analysis.

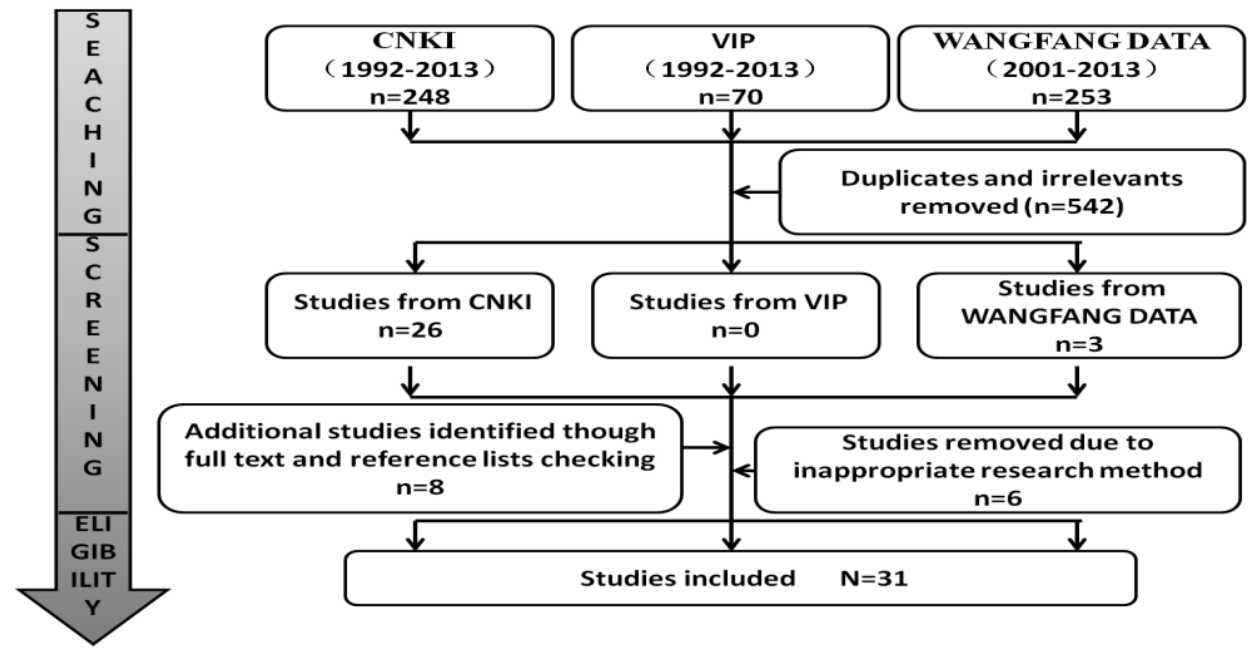

Figure 1 Flow diagram for searching, screening and identifying papers

Figure1. Flow diagram for searching, screening, and identifying papers.

The first study about physical activity of people with disabilities conducted in mainland China were published in $1992 .{ }^{7}$ However, the first eligible study for this review was published in $2003 .{ }^{11}$ In the 10 years since then, the frequency of publications in this area has been inconsistent (see Figure 2).

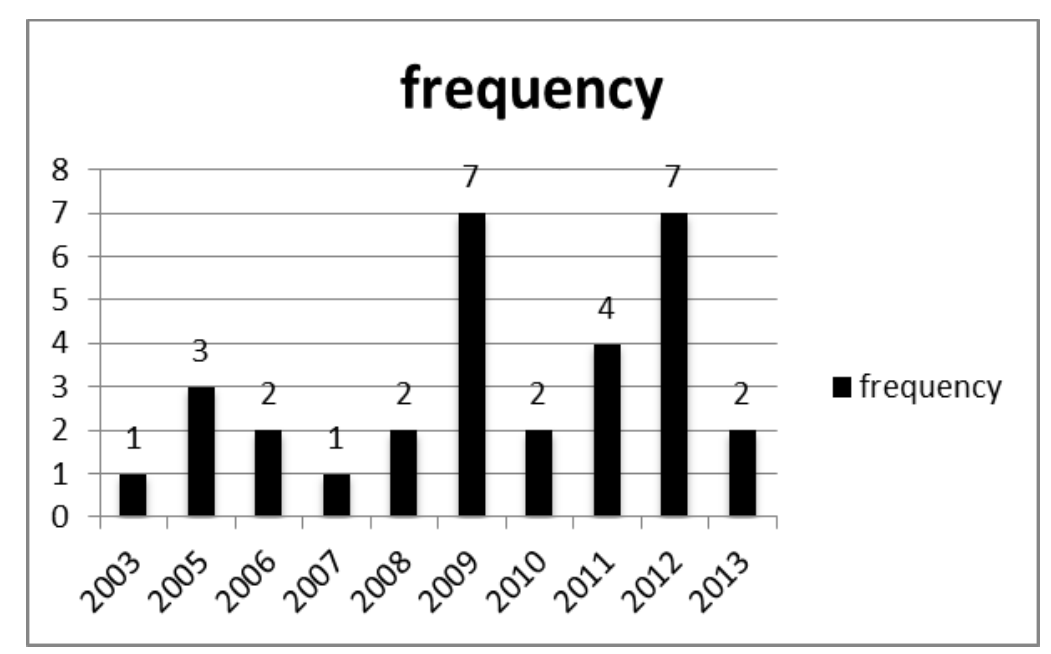

Figure2. Frequency of papers published between 2003 and 2013.

\section{RESEARCH DESIGN AND METHODOLOGIES}

All 31 studies employed a cross-sectional design (Table 1). Of these, 7 studies (22.58\%) used stratified random sampling methodologies, 2 (6.45\%) used random sampling, and $22(70.97 \%)$ provided no description on the study sampling. Twenty-eight studies (90.32\%) assessed physical activity and psychological or physiological profiles of the study participants using invalidated self- 
reports. Three studies (9.68\%) used partially empirically supported self-reports (i.e., showed reliability test results). None of the 31 studies used objective measures of physical activity. Of the 31studies, $28(90.32 \%)$ used descriptive statistics to analyze the physical activity data and $2(6.45 \%)$ reported $t$ tests and $\chi^{2}$ tests. One study $(3.23 \%)$ used cluster analysis.

Table1. Number of studies by research design, measurement, data analysis, characteristics of participants, and physical activity pattern for people with disabilities

\begin{tabular}{|c|c|}
\hline Characteristics & Reference No. \\
\hline $\begin{array}{l}\text { Research design } \\
\text { Cross-sectional design }(\mathrm{n}=31)\end{array}$ & $11-41$ \\
\hline $\begin{array}{l}\text { Sampling } \\
\text { Stratified random sampling }(\mathrm{n}=7) \\
\text { Random sampling }(\mathrm{n}=2) \\
\text { No information about sampling }(\mathrm{n}=22)\end{array}$ & $\begin{array}{l}11,14,19,21,25,36,39 \\
29,30 \\
12,13,15-18,20,22-24,26,27,28,31-35,37,38,40,41\end{array}$ \\
\hline $\begin{array}{l}\text { Measurement } \\
\text { Invalidated self-reports }(n=28) \\
\text { Partial empirically supported self-reports }(n=3)\end{array}$ & $\begin{array}{l}11-20,22,24-27,28-36,38-41 \\
21,23,37\end{array}$ \\
\hline $\begin{array}{l}\text { Data analysis } \\
\text { Descriptive statistics }(\mathrm{n}=28) \\
\mathrm{T} \text { test or } \chi^{2} \text { test }(\mathrm{n}=2) \\
\text { Cluster analysis }(\mathrm{n}=1)\end{array}$ & $\begin{array}{l}11-16,18-27,28-33,35-39,41 \\
17,34 \\
40\end{array}$ \\
\hline $\begin{array}{l}\text { Disability type } \\
\text { Hearing disability }(\mathrm{n}=4) \\
\text { Physical disability }(\mathrm{n}=1) \\
\text { Hearing, visual, intellectual disabilities }(\mathrm{n}=1) \\
\text { Minority with disabilities }(\mathrm{n}=1) \\
\text { Variety of disabilities }(\mathrm{n}=24)\end{array}$ & $\begin{array}{l}19,32,34,37 \\
23 \\
13 \\
30 \\
11,12,14-18,20-22,24-27,28-29,31,33,35,36,38-41\end{array}$ \\
\hline $\begin{array}{l}\text { Sample size } \\
<100(\mathrm{n}=2) \\
<1000(\mathrm{n}=24) \\
\geq 1000(\mathrm{n}=5)\end{array}$ & $\begin{array}{l}24,36 \\
12-20,23,25-27,28-30,32-35,37-38,40,41 \\
11,21,22,31,39\end{array}$ \\
\hline $\begin{array}{l}\text { Participants' diversity } \\
\text { Undergraduate students }(n=4) \\
\text { Children and adolescents }(n=2) \\
\text { Citizens }(n=25)\end{array}$ & $\begin{array}{l}19,32,34,37 \\
13,35 \\
11,12,14-18,20-27,28-31,33,36,38-41\end{array}$ \\
\hline $\begin{array}{l}\text { Study site } \\
\text { Inside a city }(\mathrm{n}=13) \\
\text { Inside a province }(\mathrm{n}=10) \\
\text { Different provinces }(\mathrm{n}=7) \\
\text { No information }(\mathrm{n}=1)\end{array}$ & $\begin{array}{l}14,18,20,24,27,32-38,41 \\
12,13,21,26,28-31,39,40 \\
11,15-17,19,23,25 \\
22\end{array}$ \\
\hline Demographic characteristics of participants & \\
\hline $\begin{array}{l}\text { No information }(n=9) \\
\text { One position (i.e., education, gender, } \\
\text { urban/rural) }(n=11)\end{array}$ & $\begin{array}{l}14,19,24-26,32,37-39 \\
11-13,18,20,21,22,27,34,35,41\end{array}$ \\
\hline $\begin{array}{l}\text { Two positions (i.e., education, gender, } \\
\text { urban/rural, age) }(\mathrm{n}=2)\end{array}$ & 29,40 \\
\hline $\begin{array}{l}\text { Three or more positions (i.e., gender, age, } \\
\text { education, income, occupation, urban or } \\
\text { rural, and income) }(n=9)\end{array}$ & $15-17,23,28,30,31,33,36$ \\
\hline $\begin{array}{l}\text { Education level }(\mathrm{n}=7, N=3,234) \\
\text { Primary education or under }(N=1424,44.03 \%) \\
\text { Junior or high school }(N=1632,50.46 \%) \\
\text { Vocational institute degree or above }(N=178 \text {, } \\
5.51 \%)\end{array}$ & $15,23,27,28,30,33,40$ \\
\hline $\begin{array}{l}\text { Gender }(\mathrm{n}=17, N=11,489) \\
\text { Male }(N=7,300,63.54 \%) \\
\text { Female }(N=4,189,36.46 \%)\end{array}$ & $13,15,16,17,18,20,21,22,23,28,29,30,31,34,35,36,41$ \\
\hline Ages $(\mathrm{n}=10, N=5,081)$ & $15,16,17,23,28,29,30,31,33,36$ \\
\hline Income $(\mathrm{n}=4, N=4,042)$ & $15,16,31,40$ \\
\hline Urban/Rural $(\mathrm{n}=3, N=2,159)$ & $12,30,40$ \\
\hline
\end{tabular}




\begin{tabular}{|l|l|}
\hline Disability $(\mathrm{n}=14, N=6,866)$ & $11,12,13,15,17,18,23,28,29,32,33,34,37,40,41$ \\
Hearing disability $(N=2,630,38.31 \%)$ & \\
Physical disability $(N=2,102,30.61 \%)$ & \\
Visual disability $(N=1,251,18.22 \%)$ & \\
Intellectual disability $(N=384,5.59 \%)$ & \\
Mental disability $(N=57,0.83 \%)$ & \\
Multiple disabilities $(N=442,6.44 \%)$ & \\
\hline Prevalence (n=9, $N=5,982)$ & \\
Participants met the national guidelines $(N=760$, & $14,15,16,17,18,26,28,33,39$ \\
$12.7 \%)$ & \\
\hline
\end{tabular}

\subsection{Characteristics of Studies}

Sample Size. The total sample for the 31 studies was $18,851(M=608 ; S D=539$; range: 90 to 2,605) with most studies $(n=24)$ having between 100 and 999 participants.

Study Site. Thirteen studies (41.93\%) sampled study participants from a single city. Of the remaining studies, $10(32.26 \%)$ sampled participants in multiple cities within a province and $7(22.58 \%)$ sampled participants in several cities across multiple provinces. One study $(3.23 \%)$ failed to identify the geographic location of the study site and provided no information about it.

\subsection{Demographic Characteristics of Participants}

Education. Seven studies ( $n=3,234,22.58 \%)$ provided information on the education level of the study participants. Of these participants, $44.03 \%(n=1,424)$ had a primary level of education or less and $50.46 \%(n=1,632)$ had a junior or high school degree. The remaining participants $(n=178$, $5.51 \%$ ) had education at the vocational institution level or above.

Gender. Of the 31 studies, $17(n=11,489,54.84 \%)$ identified the participants' gender, with $63.54 \%$ of participants $(n=7,300)$ being male.

Ages. Ten studies $(n=5,081,32.26 \%)$ identified the participants' ages. The majority of participants were between the ages of 16 and 65 .

Income. Among the 31 studies, four $(n=4,042,12.90 \%)$ identified the participants' monthly income level, with $67.66 \%$ of these participants $(n=2,735)$ having a monthly income level lower than 500RMB.

Urban/Rural. Of the 31 studies, three $(n=2,159,9.68 \%)$ provided information about the participants' residential location. Of these participants, $56.83 \%(n=1,227)$ lived in a rural area.

Disabilities. Fourteen studies $(n=6,866,45.16 \%)$ identified disability categories for participants. Of these, $38.31 \%$ of the participants $(n=2,630)$ had a hearing and/or speech disability. The percentages and number of participants with other disabilities included the following: physical disability $(30.61 \%$, $n=2,102)$, visual disability $(18.22 \%, n=1,251)$, intellectual disability $(5.59 \%, n=384)$, mental disability $(0.83 \%, n=57)$, and multiple disabilities $(6.44 \%, n=442)$.

\subsection{Prevalence of Physical Activity}

Across the 31 studies, a total of 760 participants $(12.7 \%)$ pooled from nine studies $(n=5,982)$ reported having a level of physical activity that met the national guidelines (Table 1). ${ }^{9}$

Physical activity type. Jogging, playing ball games, and walking were cited as the most common forms of physical activity for Chinese people with disabilities. Of these physical activities, jogging and walking were common both for males and females. However, ball games, which included three modalities - basketball, table tennis, and badminton - were most common for males.

Location. Community spaces, homes, and free open spaces were the most common places where Chinese people with disabilities carried out their physical activities.

\subsection{Differences in Physical Activity by Demographic and Disabilities}

Gender. Male participants were more physically active than their female counterparts..$^{14,21,31,41}$ In terms of activity types, activities such as ball games and resistance training were identified as the most 
common modes of physical activity for male participants, whereas for female participants aerobic dance and Tai Chi were the most common modes of physical activity. ${ }^{15,18,19,26,30,33,37,40,41}$

Age. Compared to other age groups, young adults and middle-age adults (from 16 to 50 years old) were more physically active. ${ }^{14,21,31}$. Physical activity among older adults (age 50 and older) with disabilities showed an inconsistent trend. ${ }^{14,31,33}$ In terms of specific activities, young and middle-age adults with disabilities preferred ball games as a form of physical activity. However, older adults were more likely to choose aerobic dance and traditional Chinese physical activities, such as Tai Chi and Qi-gong. ${ }^{15,26}$

Education. Higher levels of education were related to physical activity participation. ${ }^{14,40}$

Incomes. People with higher incomes (including social security insurance) were more likely to participate in physical activities. ${ }^{37}$

Living settings. People living in urban areas were more physically active than people living in rural areas. ${ }^{12,14}$ In addition, those living in urban areas had more choices for places and spaces to carry out physical activities than did those living in rural areas. ${ }^{12,40}$

Disabilities. People with a hearing disability were more likely than people with other types of disabilities to be physically active. ${ }^{11,14,18,26,33}$ In addition, people with visual impairment were less likely than people with other types of disabilities to be physically active. ${ }^{18,21,26,33}$ In terms of specific activity types, playing ball games and jogging/walking ${ }^{41}$ were reported as the most common modes of physical activity for people with a hearing disability. ${ }^{16,21,29}$ Resistance training was the most common form of physical activity for people with a visual disability. ${ }^{16,21,29,41}$

\section{DISCUSSION}

This review examines, for the first time, physical activity of Chinese people with disabilities. Findings indicated that a small percentage $(12.7 \%)$ of people with disabilities met China's physical activity guideline levels. There were differences in the levels of physical activity by demographics and living settings, with men and those with higher levels of education and incomes tending to be more physically active compared to women and those with low education and income levels; and those living in urban areas were more active than those living in rural areas.

In a national survey conducted in 2013, the General Administration of Sport of China reported that $32.7 \%$ of Chinese adults (those between 20 and 69 years old) met the standards recommended by national physical activity guidelines. ${ }^{42}$ Thus, compared to the general population, the overall level of physical activity for people with disabilities was much lower than for people without disabilities.

\subsection{Limitations and Future Studies}

One limitation of this review is that the search terms and methods used may not have captured all studies related to physical activity among Chinese citizens with disabilities. There were also significant methodological limitations in the studies reviewed. All studies were cross-sectional in design and descriptive in nature. This limitation makes it impossible to infer causality. Prospective and longitudinal studies are needed to better understand trends and patterns in physical activity over time in order to inform public health policy planning and aid in the development of targeting strategies. ${ }^{43}$ Many of the studies provided incomplete information on the study design and sampling methodologies; these limitations, along with the heterogeneity in the age of participants and the level and type of their disabilities, make it difficult to generalize the results to any one particular population of interest. More importantly, all studies used self-report measures of physical activity, raising questions regarding self-recall bias, and the validity of the study findings. Finally, the lack of a consistent definition of "disability" and "physical activity" makes it a challenge to compare results across studies, thereby limiting generalizability.

In reference to the need for future studies, people with disabilities living in urban areas were shown to be more physically active than people with disabilities living in rural areas. This finding on urbanrural disparities in the prevalence of physical activity is consistent with the results of a 2007 survey of the general Chinese population. ${ }^{44}$ With rapid urbanization in China occurring over the last three decades, this finding suggests that people living in urban areas may have greater access to physical 
activity facilities compared to those living in the rural areas. Epidemiological studies have clearly indicated urban-rural disparities in disability prevalence. ${ }^{45}$ These factors call for a more systematic research effort in order to understand patterns of physical activity in rural areas.

\section{CONCLUSION}

This review indicates that low levels of physical activity exits among people with disabilities in mainland China, and that few people with disabilities meeting established the standards set by physical activity guidelines. In addition, there are differences in physical activity levels by socioeconomic and education status and between urban and rural areas. These findings document the need for additional studies that employ rigorous designs and methodologies, including the use of objective physical activity measures.

\section{FUNDING}

This work was supported by Interdisciplinary Seed Research Funding of Zhejiang University [grant number: JCZZ-2013004].

\section{Authors' CONTRibutions}

QS drafted the manuscript. LZW and HQL conducted literature search. QS and LZW evaluated the study articles and made decisions on inclusion and exclusion of the articles. QS, PDL and BJC performed statistical analyses. All authors (QS, LZW, HQL, PDL and BJC) were involved in the manuscript development and its revision. All authors read and approved the final manuscript.

\section{DeClaRATION OF CONFLICTING INTERESTS}

The author(s) declare that they have no competing interests.

\section{REFERENCES}

[1] U. S. Department of Health and Human Services. 2008 Physical Activity Guidelines for Americans. Available at: http://health.gov/paguidelines/guidelines/. Accessed February 2016.

[2] World Health Organization. Physical In activity: A Global Public Health Problem. Available at: http://www.who.int/dietphysicalactivity/factsheet_inactivity/en/. Accessed February 2016.

[3] U. S. Department of Health and Human Services. The 2005 Surgeon General's call to action to improve the health and wellness of persons with disabilities. Atlanta, GA: U.S. Department of Health and Human Services. Available at: http://www.ncbi.nlm.nih.gov/books/NBK44667/. Accessed February 2016.

[4] Centers for Disease Control and Prevention. Physical activity among adults with a disability - United States, 2005.Morbility and Mortality Weekly Report (MMWR), 2007; 56:1021-1024.

[5] Rimmer JH. Exercise and physical activity in persons aging with a physical disability. Physical Medicine \& Rehabilitation Clinics North Am, 2005; 16:41-56.

[6] Leading Group of the Second National Sample Survey on People with Disabilities \& National Bureau of Statistics. Bulletin No.2 of the Second National Sample Survey on Disabled. Retrieved from: http://www.cdpf.org.cn/sytj/content/2007-11/21/content_30316035.htm. 2006.

[7] Yan S, Yao YW. Current physical activity status and strategic thinking for people with disabilities in Tianjin city. J Tianjin Uni Sport, 1992; 4:74-78.

[8] Rimmer JH, Chen MD, McCubbin JA, Drum C, Peterson J. Exercise intervention research on person with disabilities: What we know and where we need to go. Am J Phys Med Rehabili, 2010; 89:249-263.

[9] Qiu J. Theoretical and empirical research to explore Chinese Sports Population. Beijing Sport University Press, 2002.

[10] Carlos MC, Wendell CT. Physical activity interventions in adult populations with disabilities: A review. Quest, 2003;63: 385-410.

[11] Li ZJ, Chi TL, Shao JM, Zhang P, Lu ZN, Wang XY. Current situation and countermeasures for fitness training and physical activity of urban people with disabilities in China. Shanghai Sport Sci Res, 2003;24(1): 13-15.

[12] Gao X.A. The restrictive factors of sports of the disabled in Gansu and countermeasures. Journal of Physical Education, 2005; 12(1): 49-52.

[13] Zhu WD, Ye W and Li WH. Research on current situation and strategy of physical education of the handicapped in Jiansu province. Journal of Beijing Sport University, 2005; 28(4):535-537. 
[14] Zhang B, Shao JM, and Lu ZN., et al. Investigation and analysis of status quo of fitness exercise of the disabled in Shanghai. Journal of Shanghai University of Sport, 2005; 29(5): 74-78.

[15] Wang W and Wang J. Investigation of physical training style of city disabled people in China. Journal of Wuhan Institute of Physical Education, 2006;40(3): 45-48.

[16] Xu CL, Tian J, and Wang J. Present situation of disabled people participating in activities of whole national fitness and countermeasures. Journal of Shanghai University of Sport, 2006;30(1): 82-85.

[17] Liang ZS and Feng XH. Investigation and analysis of factors affecting disabled people's physical exercises in China. Chinese Journal of Special Education, 2007;12: 14-18.

[18] Li G, Yang J and Chen CC. Analysis and investigations of disabled fitness activity in Rizhao of Shandong Province. Journal of Jilin Institute of Physical Education, 2008;24(5): 156-157.

[19] Hu SX. A research on the situation of deaf college students' after school physical activities. Journal of Zhongzhou University, 2008;25(6): 97-99.

[20] Dai JS, Sun B and Wu L., et al. Current situation and influencing factors of physical exercises of disabled persons in Nanjing. Journal of Wuhan Institute of Physical Education, 2009; 43(2): 97-100.

[21] Yu J, Li YX and Sun MJ. Research on developing condition of disabled sports in Shangdong province. China Sport Science, 2009; 29(8): 65-72.

[22] Ma ZY, Zhang J and Su LN., et al. Status quo and development of sports life for Chinese invalids in the context of caring about people's life. Journal of Chengdu Sport University, 2009;35(4): 22-25.

[23] Zhang YX. Study on sport inferiority feelings of disabled in China. Bulletin of Sport Science and Technology, 2009; 17(4): 76-78.

[24] Ding HY, Wang ZB and Hu LL., et al. An investigation and research in the status of physical activity for disabled persons in Huzhou city. Journal of Anhui Sport Science, 2009; 30(4): 5-7.

[25] Sun WQ. Investigation and countermeasure of the disabled physical exercise in China. Shandong Sports Science \& Technology, 2009; 31(2): 40-43.

[26] Su WT. Investigation of sports activities of disabled in urban communities in Hubei and countermeasures. Journal of Wuhan Institute of Physical Education, 2009;43(9): 77-80.

[27] Zhang SJ. Current situation and analysis of disabled person's physical activity of Honghei zhou in Yunnan province. Science and Technology Innovation Herald, 2010; 28: 216.

[28] Liang ZS, Feng XH and Ma XJ. An investigation and analysis of the present sports life of the disabled people from small townships of Hebei province. Chinese Journal of Special Education, 2010; 3: 14-17.

[29] Gong CY. Analysis and investigations of the disabled sports in the national fitness program implementation. Journal of Anhui Sports Science, 2011;32(3): 57-58.

[30] Zeng W. Sichuan nationalities regions of the current situation and disabled people exercise countermeasures. Sichuan Sports Science, 2011;3: 113-116.

[31] Chen XZ. Study on the development strategy of the physical exercise status of disabled persons in Liaoning province. Journal of Guangzhou Sport University, 2011;31(6): 48-52.

[32] Xu WS. Current status and analysis of deaf college students' after P.E. class physical activity in Nanjing city. Kaoshi Zhoukan, 2011;66: 136-137.

[33] Dai X. Current situation and countermeasure analysis of physical fitness of disabled people in Beijing city communities. Sports Culture Guide, 2012;8: 22-24.

[34] Liu HQ. The research on impact factor young hearing-impaired students' physique health. Zhejiang Sport Science, 2012;34(3): 111-114.

[35] Li JZ and Chen JQ. Analysis on exercise consciousness and impact factors of disadvantaged students in Special school of Ganzhou city. Modern Enterprise Education, 2012; Oct: 112-113.

[36] Chang YY. Analysis of Taiyuan urban disabled using fitness paths: Taking Taiyuan city as study example. Bo Ji, 2012; 4(4): 71-73.

[37] Jin M, Nie D and Peng QY., et al. Demand and exercise behavior of college students with disabilities under all physical fitness perspective---Case study of deaf students in Tianjin city. Sports,212; 55: 152-154.

[38] Tian LG. Situation and development strategy of disabled sports in Baoding city. Kaoshi Zhoukan, 2012; 43:115.

[39] Huan LZ and Dong XH. The survey and analysis of disabled sports' development in Zhejiang province. Zhejiang Sport Science, 2012; 34(3): 45-48.

[40] Zhai SS and Yu J. Study on absence and regression of the disabled mass sports---Taking Jiaodong peninsula as an example. Bulletin of Sport Science and Technology, 2013; 21(3): 114-117. 
[41] Zhang JQ and Zhao CX. An investigate analysis on the physical exercise status of disable in Linyi. Liaoning Sport Science and Technology, 2013;35(5): 22-25.

[42] General Administration of Sport of China. Bulletin of 20 to 69 years old adults' physical activity and physical fitness sample survey in ten provinces and cities. Retrieved from: http://www.sport.gov.cn/ n16/n1107/n1788/4428310.html.

[43] Rimmer, J.H., Braddock, D., \& Pitetti, K.H. Research on physical activity and disability: an emerging national priority. Medicine \& Science in Sport \& Exercise, 1996;28(11): 1366-1372.

[44] General Administration of Sport of China. Bulletin of 2007 Chinese urban and rural residents' physical activity prevalence survey. Retrieved from: http://www.gov.cn/test/2012-04/19/content_2117453.htm.

[45] Zheng, X.Y., Chen, G., \& Song, X.M., Liu, J.F., Yan, L.J., Du.W, Zhang, J. Twenty-year trends in the prevalence of disability in China. Bulletin of the World Health Organization, 2011;89: 788-797.

Citation: Qi Si, et al. "A Systematic Review of Physical Activity among People with Disabilities in Mainland China: From 1992 To 2013." International Journal of Sports and Physical Education (IJSPE), vol 3, no. 4, 2017, pp. 17-25. doi:http://dx.doi.org/10.20431/2454-6380.0304004.

Copyright: (C) 2017 Authors. This is an open-access article distributed under the terms of the Creative Commons Attribution License, which permits unrestricted use, distribution, and reproduction in any medium, provided the original author and source are credited. 